\title{
Structural Evolution and Internal Stress of Nickel-Phosphorus Electrodeposits
}

\author{
C. S. Lin, ${ }^{\text {a,z }}$ C. Y. Lee, ${ }^{\text {b }}$ F. J. Chen, ${ }^{a}$ and W. C. Li $^{\mathrm{a}}$ \\ ${ }^{a}$ Department of Materials Science and Engineering, National Taiwan University, Taipei 106, Taiwan \\ ${ }^{b}$ Department of Mechanical and Automation Engineering, Da-Yeh University, Da-Tsuen, \\ Changhua 515, Taiwan
}

\begin{abstract}
The properties of nickel-phosphorus (Ni-P) electrodeposits can be best related to their phosphorus content and microstructure. This study systematically investigated the microstructural evolution and mechanical properties of the deposits plated from nickel sulfamate baths containing $0-40 \mathrm{~g} \mathrm{dm}^{-3}$ phosphorous acid $\left(\mathrm{H}_{3} \mathrm{PO}_{3}\right)$. Experimental results indicate that coarse nickel grains were substantially refined with the incorporation of phosphorus into the deposit. For example, as the deposit phosphorus content was increased from 0 to $14 \mathrm{wt} \%$, the structure of the deposit changed in sequence from a coarse column to a mixture of column and lamella, followed by a well-defined lamella, and finally to a homogeneous amorphous matrix dispersed with nanosized grains. Accompanied with this structural evolution, the deposit exhibited a distinct change in deposit hardness and internal stress. These properties and microstructure relationships are discussed in terms of the lattice defects in the grains and proton discharge during electroplating.
\end{abstract}

(C) 2005 The Electrochemical Society. [DOI: 10.1149/1.1901064] All rights reserved.

Manuscript submitted July 27, 2004; revised manuscript received November 25, 2004. Available electronically April 22, 2005.

Because electrodeposited and electroless nickel-phosphorus alloys are extensively used as protective coatings ${ }^{1-4}$ or electrodes ${ }^{4-11}$ for electrochemical catalysis, understanding nickel and phosphorus codeposition mechanism, and the microstructures as well as physiochemical properties of the deposits, is now all the more important. For electrodeposition using phosphorus oxyacid as the source of phosphorus in the deposit, two codeposition mechanisms have been proposed: direct mechanism and indirect mechanism. Some researchers such as Brenner ${ }^{12}$ first and recently Morikawa et al., ${ }^{13}$ considered the direct codeposition mechanism as $\mathrm{Ni}^{2+}$ and phosphorus oxyacid being directly reduced to nickel and phosphorus adatoms, which then combine to form $\mathrm{Ni}_{n} \mathrm{P}$ solid solution. For the indirect codeposition mechanism, phosphorus oxyacid is reduced to phosphine which then, in the presence of $\mathrm{Ni}^{2+}$, is oxidized to phosphorus adatoms, while $\mathrm{Ni}^{2+}$ are simultaneously reduced to nickel. ${ }^{1,14-17}$

The microstructure of Ni-P electrodeposits has been extensively studied, in particular the crystalline to amorphous transition of the deposits as their deposit phosphorus content increases. Bredael et $a l .{ }^{18}$ studied the recrystallization behaviors of Ni-P electrodeposits using X-ray diffraction (XRD) and transmission electron microscopy (TEM), and noted the Ni-P alloy changes from crystalline to amorphous as its deposit phosphorus content exceeds 11.6 -13.1 wt \%. By employing TEM, Vafaei-Makhsoos et al. ${ }^{19}$ characterized the alloys with 3.8 and $6.7 \mathrm{wt} \%$ phosphorus as a solid solution composed of micrometer-sized grains, and the alloys containing 11.7 and $13 \mathrm{wt} \%$ as an amorphous matrix dispersed with micrometer-sized crystals. Studied with cross-sectional highresolution TEM, the $\mathrm{Ni}_{77} \mathrm{P}_{23}$ alloy (with $13.6 \mathrm{wt} \%$ phosphorus), which has been characterized as amorphous by XRD, is identified as an amorphous matrix dotted with nanosized crystals, as illustrated by Shimizu et al. ${ }^{20}$ The notable inconsistency about the deposit phosphorus content at which crystalline-to-amorphous transition occurs may be due to the different characterization methods and the various solutions employed for electrodeposition.

$\mathrm{Ni}-\mathrm{P}$ electrodeposits are potentially applied as the protective coatings with good wear resistance and as the electroformed structures which possess better high-temperature strength than the pure nickel electrodeposit if the internal stress of the deposits can be well controlled. Although pure nickel plated from the nickel sulfamate bath has lower internal stress than that deposited from the sulfate and chloride baths, ${ }^{21-23}$ the Ni-P electrodeposits plated from the nickel sulfamate bath is less well studied comparing to its nickel

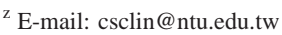

sulfate and citrate counterparts. In this study, the Ni-P alloys with various phosphorus contents were electroplated from nickel sulfamate baths through the additions of distinct amounts of $\mathrm{H}_{3} \mathrm{PO}_{3}$. The mechanical properties of the deposits, such as hardness and internal stress, were found to correlate well to the structural evolution of the deposits as their deposit phosphorus content was increased.

\section{Experimental}

Electroplating.- Ni-P electrodeposits were plated onto copper plates. The copper plates were mechanically polished using emery paper up to grade 2400 , rinsed with deionized water, and cleaned in acetone ultrasonically, and finally dried using a stream of hot air. Prior to electroplating, the plates were activated in 5\% sulfuric acid at room temperature. The nickel sulfamate bath was composed of $90 \mathrm{~g} \mathrm{dm}^{-3}$ of nickel ions as nickel sulfamate, $3 \mathrm{~g} \mathrm{dm}^{-3}$ nickel chloride, $40 \mathrm{~g} \mathrm{dm}^{-3}$ boric acid, and $0.4 \mathrm{~g} \mathrm{dm}^{-3}$ sodium dodecyl sulfate as a wetting agent. To electroplate the Ni-P alloys with various amounts of phosphorus, $1-40 \mathrm{~g} \mathrm{dm}^{-3} \mathrm{H}_{3} \mathrm{PO}_{3}$ was added to the sulfamate bath. A $2.5 \mathrm{dm}^{3}$ solution at $50^{\circ} \mathrm{C}$ was used for electroplating and was continuously stirred by a stream of room-temperature air throughout the electroplating. The electroplating was performed galvaostatically at $8 \mathrm{~A} \mathrm{dm}^{-2}$. The copper plates before and after electroplating were weighted, respectively, by an electronic balance with an accuracy of $0.1 \mathrm{mg}$. The mass of the deposit was the mass difference of the copper plate with and without the deposit.

Microstructural characterization.-The composition of the deposits was measured by electron microprobe analysis (EPMA) and reported as an average of five measurements. Once the composition and mass of the deposit plated with a given charge were known, the current efficiency could be calculated on the assumption that reduction of one $\mathrm{Ni}^{2+}$ and $\mathrm{H}_{3} \mathrm{PO}_{3}$ to nickel and phosphorus involves the transfer of two and three electrons, respectively. The overall grain structure of the deposits was characterized using an optical microscope $(\mathrm{OM})$ on the cross sections etched by a solution composed of nitric acid and ammonium. XRD was performed to identify the crystal structure of the deposits. Finally, detailed microstructure of the deposits was investigated by cross-sectional TEM on the specimens prepared by a combined mechanical grinding and ion-beam thinning technique. The composition of the deposit was also measured via electron energy-dispersive spectroscopy (EDS) equipped in TEM as a supplement of the EPMA measurement. Both EDS and EPMA results were quantified using internal standards associated with the equipment. The structure of the deposit was characterized via the selected-area diffraction (SAD) technique.

Deposit hardness and internal stress measurement.-The hardness of the deposit was measured on the polished cross section with 


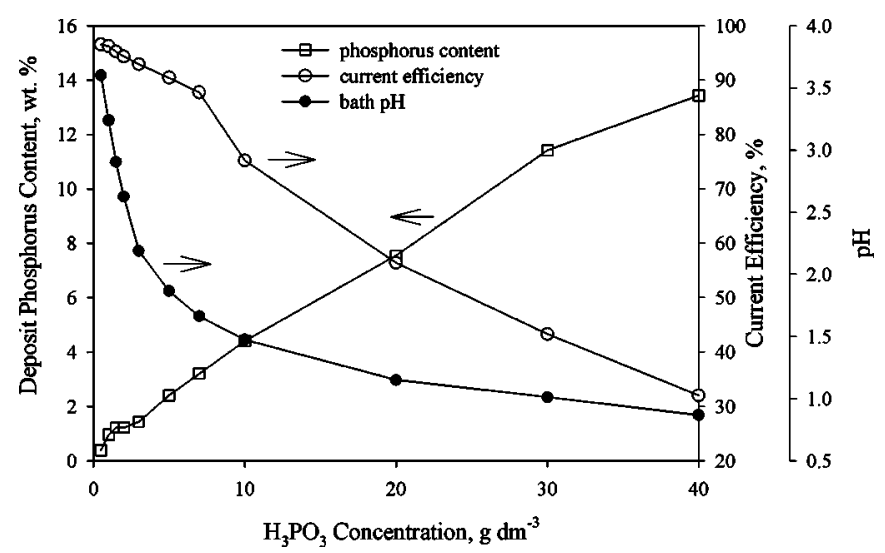

Figure 1. Bath $\mathrm{pH}$, deposit phosphorus, and current efficiency as a function of bath $\mathrm{H}_{3} \mathrm{PO}_{3}$ concentration.

an applied load of $50 \mathrm{~g}$. The reported hardness of each deposit was an average of eight measurements. The internal stress of the deposits was measured using a flexible strip method via a model 683 deposit stress analyzer. The Ni-P deposit was plated onto one side of a thin copper strip of which the other side was passivated with a nonconductive varnish. The internal stress of the deposit caused the bending of the test strip. In conjunction with the thickness of the coating, the internal stress was calculated based on the calibrated constant of the copper cathode provided by the manufacturer. Because the internal stress measured by this method depends on the thickness of the deposit, except otherwise stated, the internal stress was measured as the Ni-P deposits grew to a thickness of approximately $3 \mu \mathrm{m}$. The internal stress, which represented the average stress in the deposit, was reported as an average of three measurements.

\section{Results}

Composition and current efficiency of the deposits. - Figure 1 shows the $\mathrm{pH}$ of the bath and the phosphorus content as well as the current efficiency of the deposits as a function of $\mathrm{H}_{3} \mathrm{PO}_{3}$ concentration. Adding $\mathrm{H}_{3} \mathrm{PO}_{3}$ to the nickel sulfamate bath reduced the bath $\mathrm{pH}$, which meanwhile led to the formation of Ni-P deposits. The deposit phosphorus content increased linearly with increasing $\mathrm{H}_{3} \mathrm{PO}_{3}$ concentration, while the current efficiency decreased with the $\mathrm{H}_{3} \mathrm{PO}_{3}$ concentration. It was previously shown that the deposits plated from nickel sulfate baths and citrate baths also contain higher phosphorus as $\mathrm{H}_{3} \mathrm{PO}_{3}$ concentration is increased. ${ }^{13,24-26}$ In general, the more $\mathrm{H}_{3} \mathrm{PO}_{3}$ is added in the bath, the higher the proton activity becomes. Consequently, reduction of protons can be enhanced as more $\mathrm{H}_{3} \mathrm{PO}_{3}$ is added, which, in turn, reduces the current efficiency. The current efficiency of the Ni-P deposit plated from the nickel sulfate bath has been shown to decrease with increasing $\mathrm{H}_{3} \mathrm{PO}_{3}$ concentration, ${ }^{24-26}$ while that plated from the nickel citrate has a maximum current efficiency in the presence of intermediate amounts of $\mathrm{H}_{3} \mathrm{PO}_{3}$.

Cross-sectional OM observations.-Figure 2 shows a series of cross-sectional OM micrographs of the deposits plated from the nickel sulfamate baths containing different amounts of $\mathrm{H}_{3} \mathrm{PO}_{3}$. When plated at a constant current density, the deposit plated from the sulfamate nickel bath without $\mathrm{H}_{3} \mathrm{PO}_{3}$ exhibited a coarse columnar structure (Fig. 2a). These columnar nickel grains grew along the direction of the applied electric field and represented a characteristic of the grain structure of metals electroplated from simple baths. ${ }^{27,28}$ Adding $1 \mathrm{~g} \mathrm{dm}^{-3} \mathrm{H}_{3} \mathrm{PO}_{3}$ into the bath slightly refined the columnar grains as illustrated in Fig. 2b. Figure $2 \mathrm{~b}$ also shows a lamellar contrast running parallel to the coating/substrate interface. Therefore, these lamellae were notably perpendicular to the columnar grains. Figure $2 \mathrm{c}$ shows that the columnar structure was completely replaced by a layered structure when $\mathrm{H}_{3} \mathrm{PO}_{3}$ concentration was fur-

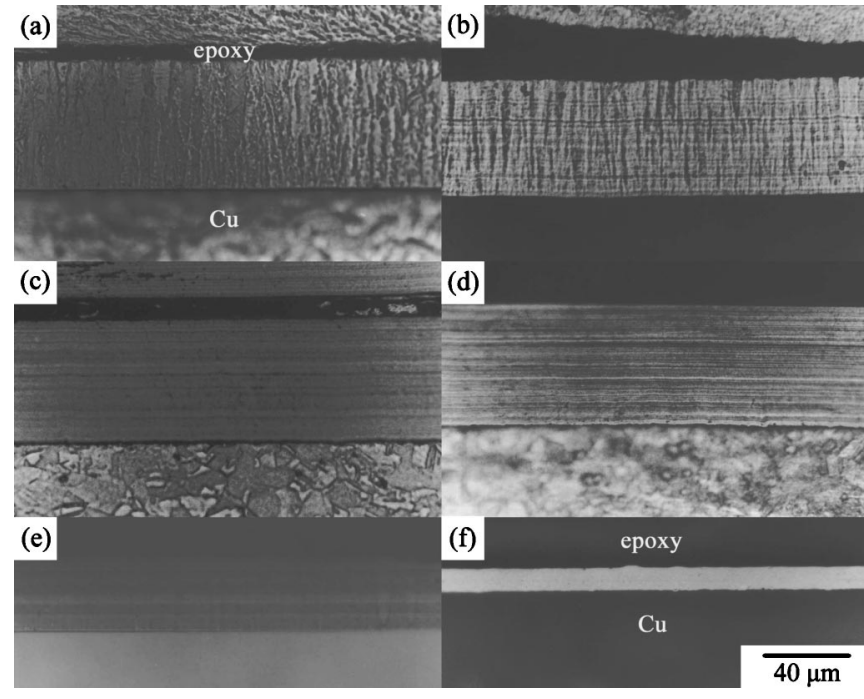

Figure 2. OM micrographs of (a) pure nickel and the Ni-P deposits plated from the bath containing (b) 1 , (c) 1.5 , (d) 10 , (e) 20 , and (f) $40 \mathrm{~g} \mathrm{dm}^{-3}$ $\mathrm{H}_{3} \mathrm{PO}_{3}$.

ther increased to $1.5 \mathrm{~g} \mathrm{dm}^{-3}$. It was also noted that the deposits plated from the baths with the addition of $2-20 \mathrm{~g} \mathrm{dm}^{-3} \mathrm{H}_{3} \mathrm{PO}_{3}$ remained to be a layered structure. However, the grain structure of the deposits plated from the baths containing 30 and $40 \mathrm{~g} / \mathrm{dm}^{3} \mathrm{H}_{3} \mathrm{PO}_{3}$ was so fine that even after proper chemical etching, the deposit plated from the bath with $40 \mathrm{~g} \mathrm{~m}^{-3} \mathrm{H}_{3} \mathrm{PO}_{3}$ showed a bright and featureless contrast (Fig. 2f).

XRD analysis. - Figure 3 shows the XRD patterns of the various deposits. The pure nickel deposit exhibited a [100] texture because the intensity ratio of (200) to (111) diffractions associated with the deposit was larger than that with nickel powders. For nickel powders the intensity ratio of (200):(111) diffractions approximately equals 0.5 . Such a [100] texture was retained when $1 \mathrm{~g} \mathrm{dm}^{-3} \mathrm{H}_{3} \mathrm{PO}_{3}$ was added to the solution. The development of lamellar structure shown in Fig. $2 b$ seems to have no effect on the texture of the columnar grains. When bath $\mathrm{H}_{3} \mathrm{PO}_{3}$ concentration was further increased to $1.5 \mathrm{~g} \mathrm{dm}^{-3}$, a distinct change in deposit texture was observed, i.e., the deposit exhibited a random orientation. As more $\mathrm{H}_{3} \mathrm{PO}_{3}$ was added to the baths, the most striking feature on the XRD patterns is

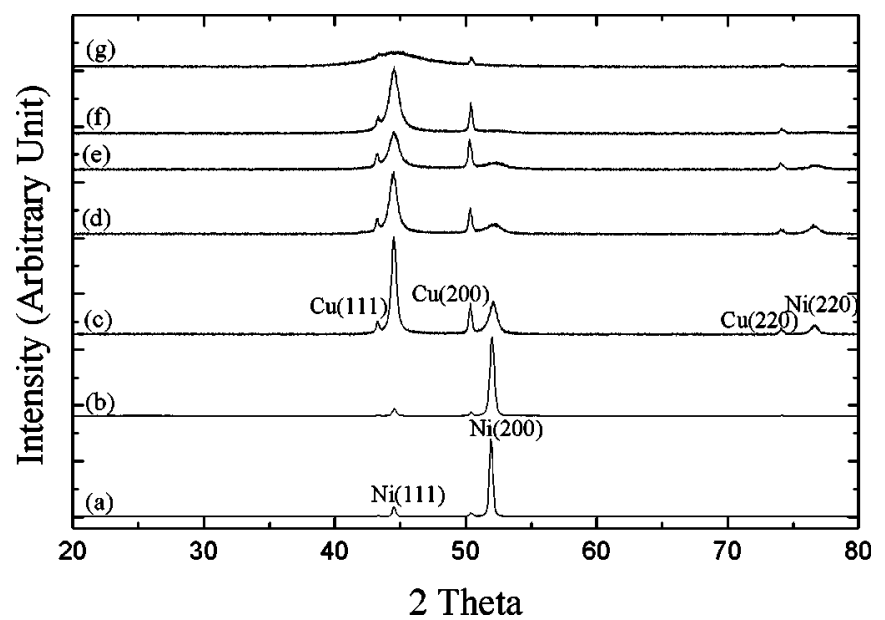

Figure 3. XRD patterns of (a) pure nickel and the Ni-P deposits plated from the bath containing (b) 1 , (c) 1.5 , (d) 5 , (e) 10 , (f) 20 , and (g) $40 \mathrm{~g} \mathrm{dm}^{-3}$ $\mathrm{H}_{3} \mathrm{PO}_{3}$. 


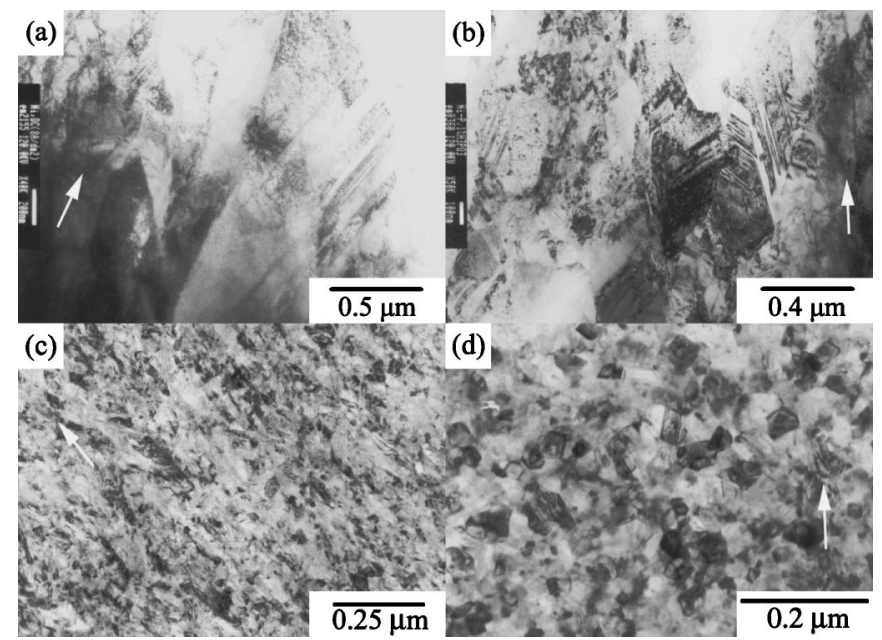

Figure 4. Cross-sectional TEM micrographs: (a) pure nickel and the Ni-P deposits plated from the baths containing (b) 1 , (c) 5 , and (d) $10 \mathrm{~g} \mathrm{dm}^{-3}$ $\mathrm{H}_{3} \mathrm{PO}_{3}$. The arrow indicates the growth direction of the deposit.

the broadening of the diffraction peaks, particularly the (200) peak. A very broad hump was observed on the deposits plated from the bath with $40 \mathrm{~g} \mathrm{dm}^{-3} \mathrm{H}_{3} \mathrm{PO}_{3}$. This result suggests that the coating is amorphous. Because the deposit phosphorus content also increased with $\mathrm{H}_{3} \mathrm{PO}_{3}$ concentration, the codeposition of phosphorus in the nickel matrix apparently refined the grain structure of the deposits. The results presented here are consistent with previous studies ${ }^{18,24}$ showing how the deposit phosphorus content affects the grain size of the deposit. In general, the larger the deposit phosphorus content, the finer the grain size of the deposit becomes.

Cross-sectional TEM characterization.-Figure 4 shows the evolution of the grain structure with increasing deposit phosphorus content via cross-sectional TEM. Like OM characterization, the pure nickel deposit exhibited a well-defined columnar structure (Fig. 4a). Dislocations and twins were observed, and the twin planes usually inclined at an angle to the columnar axis. This relative orientation between twin plane and columnar axis is a character of the [100]orientated nickel electrodeposit plated from the nickel sulfamate bath. ${ }^{28}$ Figure $4 \mathrm{~b}$ shows the cross section of the deposit plated from the bath with the addition of $1 \mathrm{~g} \mathrm{dm}^{-3} \mathrm{H}_{3} \mathrm{PO}_{3}$. The deposit still consisted of columnar grains but had more twins and dislocations than the pure nickel deposit. However, the lamellar contrast on the chemically etched cross section was not observed by TEM. The grain refinement effect associated with codeposited phosphorus became more pronounced as $\mathrm{H}_{3} \mathrm{PO}_{3}$ concentration was increased to $5 \mathrm{~g} \mathrm{dm}^{-3}$. Figure $4 \mathrm{c}$ shows that this coating was mainly composed of fibrous grains containing significant lattice distortions. When the $\mathrm{H}_{3} \mathrm{PO}_{3}$ concentration was increased to $10 \mathrm{~g} \mathrm{dm}^{-3}$, the deposit contained relatively small equiaxed grains (Fig. 4d) but fewer lattice distortions as compared to that plated from the bath containing $5 \mathrm{~g} \mathrm{dm}^{-3} \mathrm{H}_{3} \mathrm{PO}_{3}$.

Figure 5a shows that the deposit plated from the bath with the addition of $20 \mathrm{~g} \mathrm{dm}^{-3} \mathrm{H}_{3} \mathrm{PO}_{3}$ exhibited a characteristic layered structure in which the thickness of the layer was approximately $0.2 \mu \mathrm{m}$. Figure 5a also shows that the layer boundary (marked as the double arrow) displayed a light contrast when observed along most incident electron-beam directions. This result signified the layer boundary should contain more light elements, though no composition difference was discerned between the layer boundary and the interior of the layer. Both contained around $7.6 \mathrm{wt} \%$ phosphorus, as measured by EDS analysis. The dark-field image (Fig. $5 b)$ revealed each layer consisted of nanosized grains. It was also noted that the grains of the deposit tended to grow along the direction of the imposed electric field, though these grains were roughly

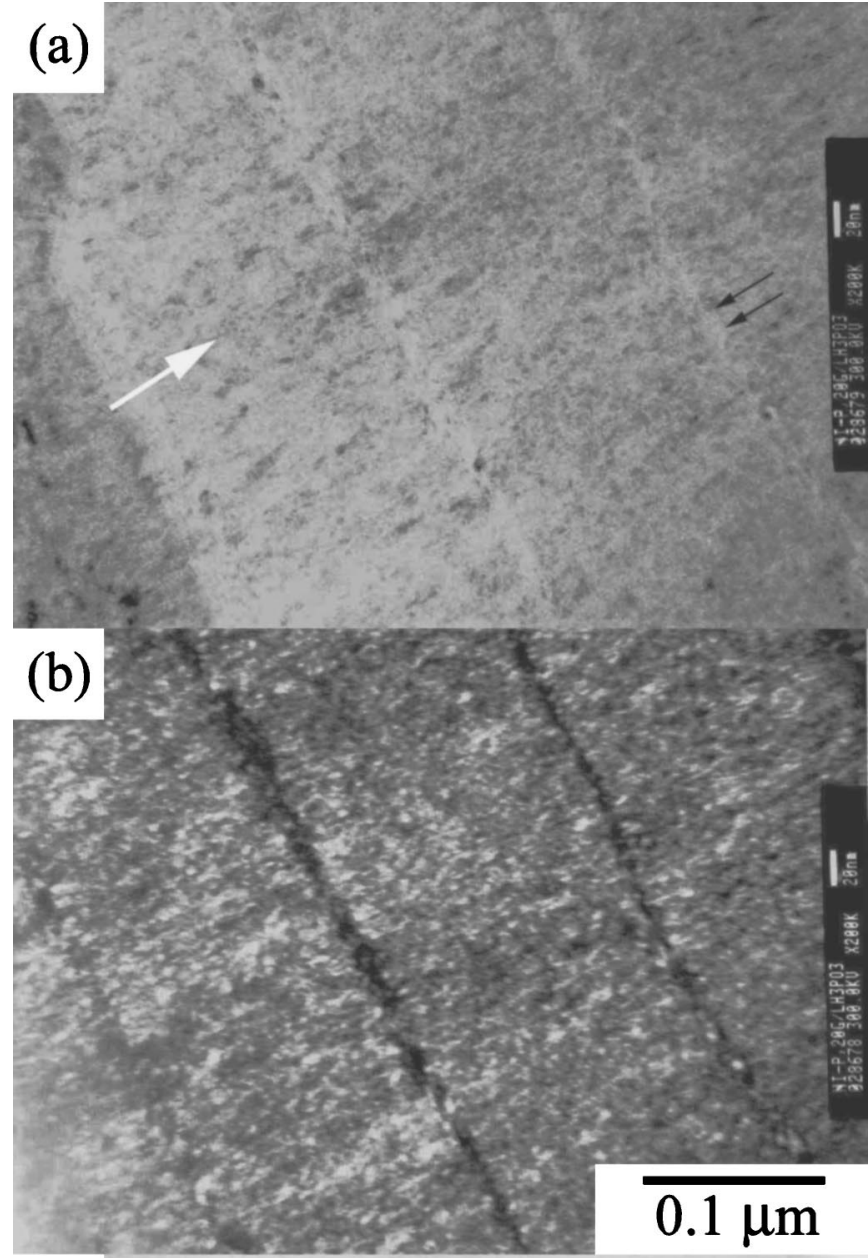

(c)

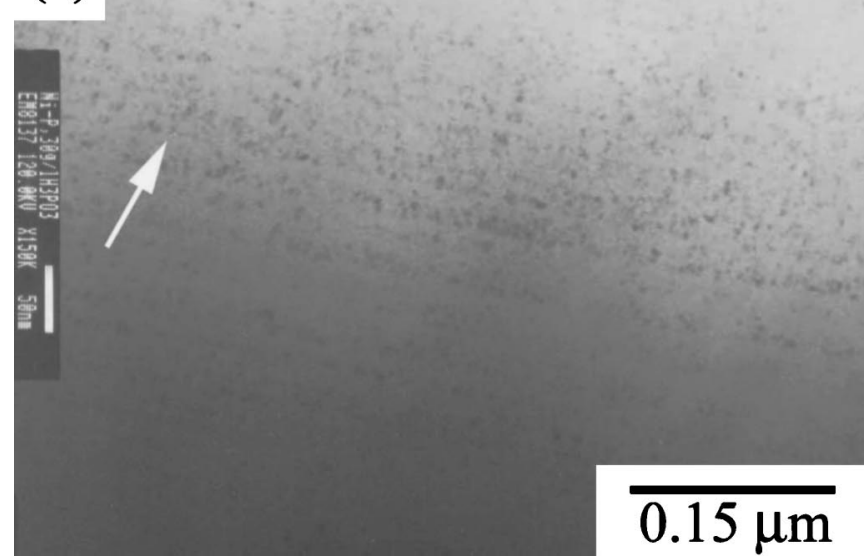

Figure 5. Cross-sectional TEM micrographs: (a,c) the Ni-P deposits plated from the baths containing 20 and $30 \mathrm{~g} \mathrm{dm}^{-3} \mathrm{H}_{3} \mathrm{PO}_{3}$, respectively, and (b) the corresponding dark-field image of Fig. 5a. The arrow shown in each figure indicates the growth direction of the deposit.

equiaxed. When $\mathrm{H}_{3} \mathrm{PO}_{3}$ concentration was increased to $30 \mathrm{~g} \mathrm{dm}^{-3}$, the layer thickness and average grain size of the deposit were further reduced, as shown in Fig. 5c. This decrease in layer thickness was more prominent on the deposit plated from the bath with $40 \mathrm{~g} \mathrm{dm}^{-3}$ $\mathrm{H}_{3} \mathrm{PO}_{3}$. Figure 6 shows that the layered structure was no longer observed on this deposit. Instead, the deposit was a homogeneous structure composed of amorphous matrix with dispersed nanosized crystals. The size of these nanograins, as measured on the dark-field 

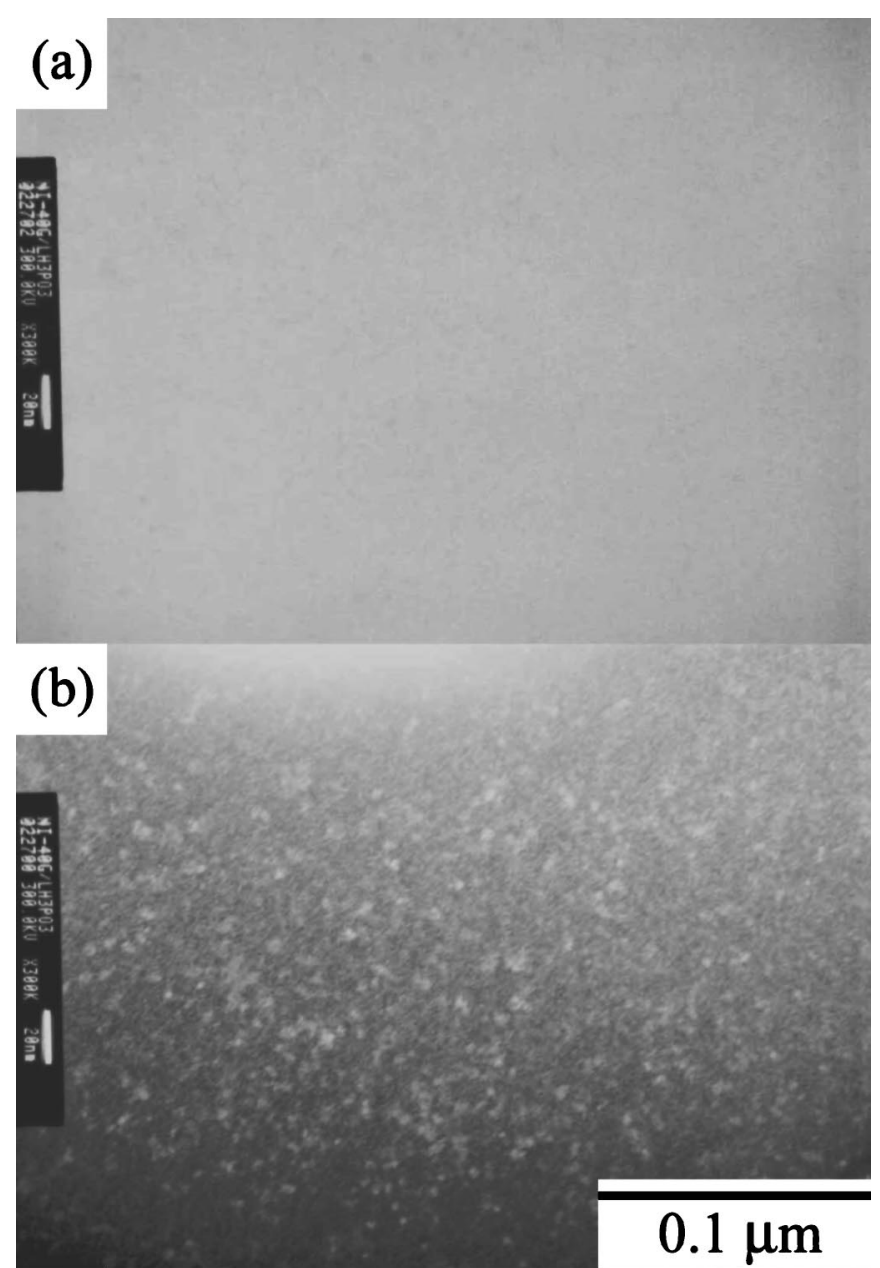

(c)

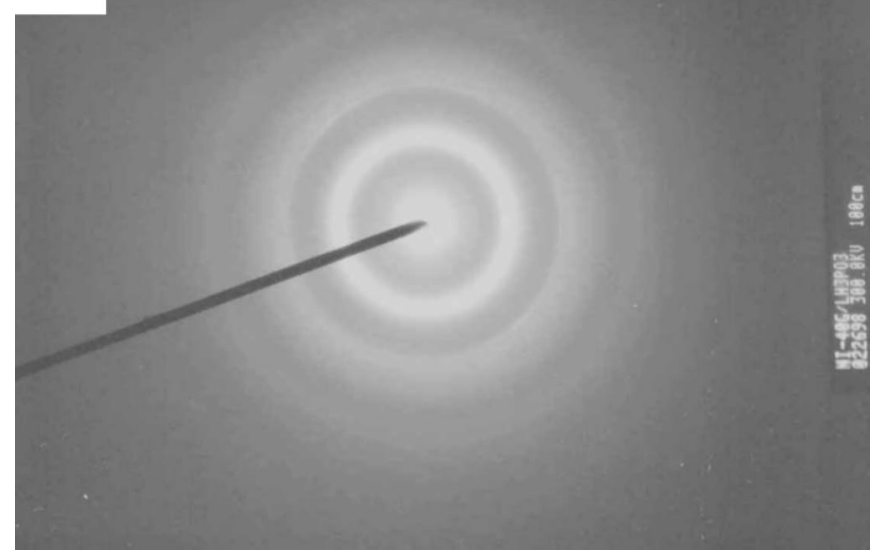

Figure 6. Cross-sectional TEM micrographs of the Ni-P deposit plated from the bath containing $40 \mathrm{~g} \mathrm{dm}^{-3} \mathrm{H}_{3} \mathrm{PO}_{3}$ : (a) bright-field, (b) dark-field images, and (c) SAD pattern.

image (Fig. 6b), was estimated to be $2 \mathrm{~nm}$. Figure $6 \mathrm{c}$ shows the SAD pattern of the deposit. These diffuse halos suggest that the deposit is amorphous, and this finding is consistent with the broadened humps shown in the XRD pattern (Fig. 3g).

Deposit hardness and internal stress.-Figure 7 shows the hardness and internal stress of various deposits as a function of $\mathrm{H}_{3} \mathrm{PO}_{3}$ concentration. Following a sharp initial increase with the addition of $\mathrm{H}_{3} \mathrm{PO}_{3}$, the deposit hardness steadily increased with increasing

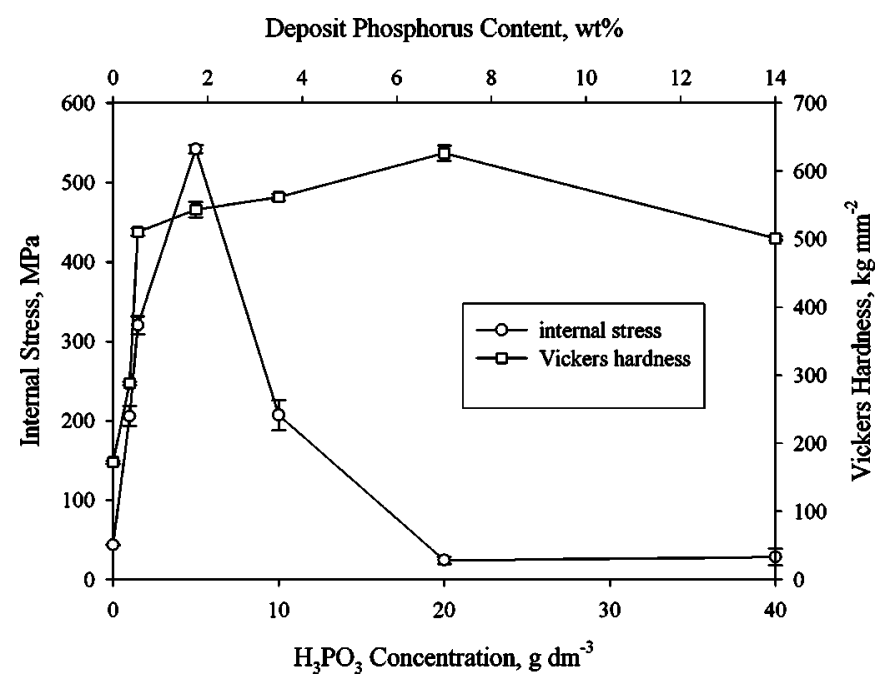

Figure 7. Effect of bath $\mathrm{H}_{3} \mathrm{PO}_{3}$ concentration on the hardness and tensile stress in the deposit.

$\mathrm{H}_{3} \mathrm{PO}_{3}$ concentration up to $20 \mathrm{~g} \mathrm{dm}^{-3}$. Further increase in $\mathrm{H}_{3} \mathrm{PO}_{3}$ resulted in a slight decrease in the hardness. The transition from a steep to a gradual increase in the hardness coincides with the stages when the deposits exhibited a distinct layered structure after chemical etching, as shown in Fig. 2b and c. Moreover, the deposit associated with the subsequent increase in the $\mathrm{H}_{3} \mathrm{PO}_{3}$ concentration underwent a decrease in the hardness as it displayed a featureless structure after chemical etching.

Figure 7 also shows the internal stress as a function of deposit phosphorus content, in which the usual sign conventions for stress were adopted, i.e., positive for tensile and negative for compressive. Like the deposit hardness, a sharp increase in the internal stress associated with the deposit was observed as long as a small amount of phosphorus was incorporated in the nickel matrix. After the internal stress reached a peak value, an abrupt decrease was observed when $\mathrm{H}_{3} \mathrm{PO}_{3}$ concentration was increased from 5 to $10 \mathrm{~g} \mathrm{dm}^{-3}$. Further increase in $\mathrm{H}_{3} \mathrm{PO}_{3}$ concentration from 20 to $40 \mathrm{~g} \mathrm{dm}^{-3}$ caused a slight change in the internal stress.

\section{Discussion}

Formation of layered Ni-P alloy electrodeposits.-The phosphorus content of Ni-P electrodeposits increases with increasing $\mathrm{H}_{3} \mathrm{PO}_{3}$ concentration; meanwhile the deposit, as characterized by $\mathrm{OM}$ on the chemically etched cross section, evolves from a columnar structure to a mixture of column and lamella, then a characteristic layered structure, and finally a featureless structure. Concomitantly, the grain structure is refined with the incorporation of phosphorus in the deposit. The literature clearly demonstrates that the incorporation of phosphorus refines the grain structure of Ni-P electrodeposits. ${ }^{18,24}$ The deposits could become amorphous when the deposit phosphorus content exceeds a critical value. ${ }^{18-20,24}$ Moreover, some electrodeposited and electroless Ni-P alloys have been shown to exhibit a layered structure after proper chemical etching. ${ }^{1,23,29}$ However, OM and TEM characterization on the Ni-P electrodeposits with a whole composition spectrum remains essential to elucidate the mechanism related to the formation of layered deposits.

The results presented here clearly illustrate that increasing bath $\mathrm{H}_{3} \mathrm{PO}_{3}$ concentration reduces the current efficiency because more cathodic charges are expended in reduction of protons. Proton reduction results in the atomic and molecular forms of hydrogen. Both can be incorporated in the deposit as atomic or molecular forms, ${ }^{8,29,30}$ which affects the texture ${ }^{31}$ and internal stress ${ }^{23,26,32}$ of the coating. In the meantime, hydrogen molecules can also merge to form hydrogen bubbles clinging to the surface of the electrode (Fig. 

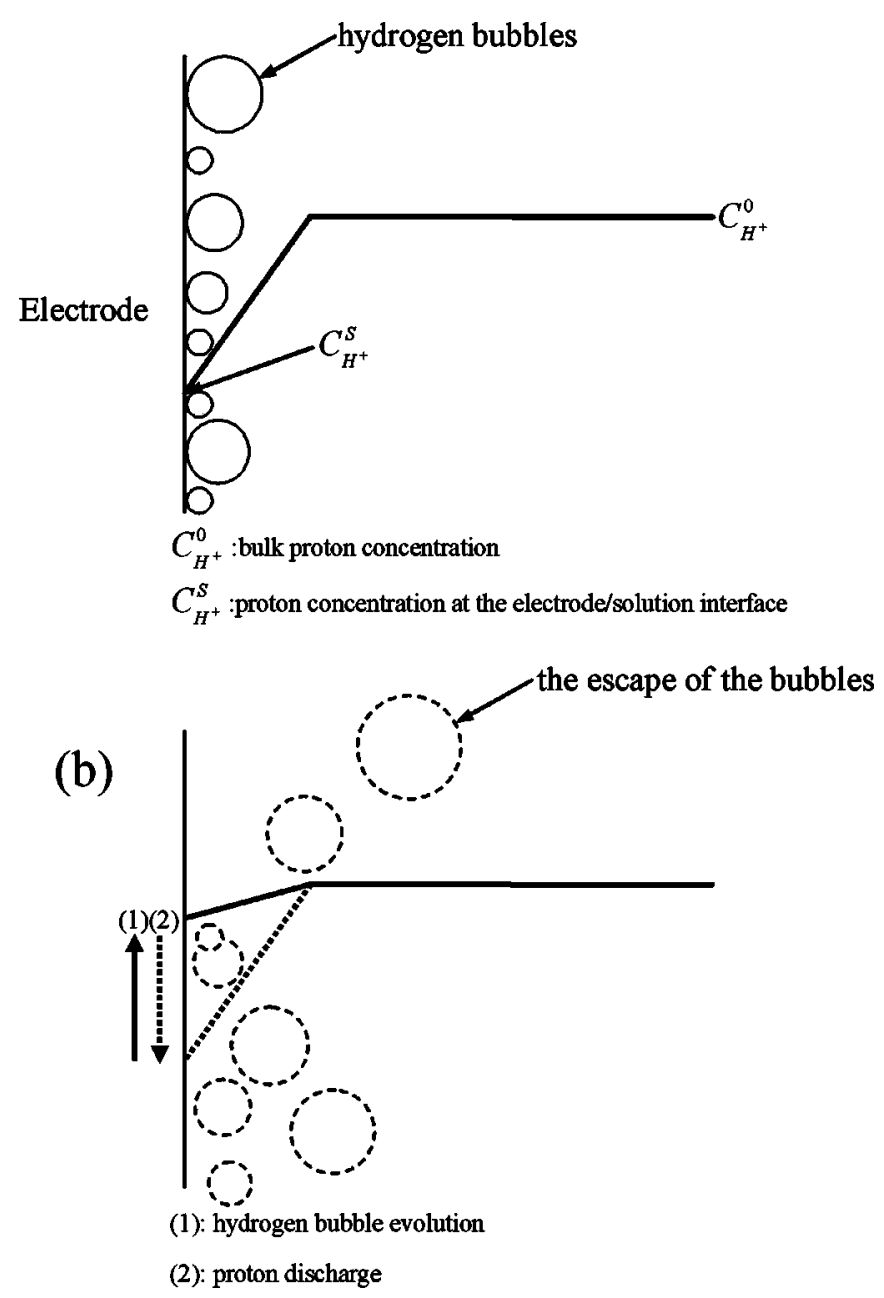

Figure 8. Schematic representations illustrating the periodic variations in interfacial proton concentration as electroplating proceeds: (a) a decrease in the proton concentration when hydrogen bubbles form due to the discharge of protons, and (b) an increase in the proton concentration when the hydrogen bubbles collapse as some of the bubbles have grown to a critical size.

8a). Furthermore, the $\mathrm{pH}$ at the electrode/solution interface rises concomitantly with the discharge of protons. ${ }^{14,29}$ Once some of the hydrogen bubbles grow to a critical size, they escape from the cathode and trigger the overall collapse of the other relatively small bubbles. Enhanced convection due to evolved gas bubbles increases the interfacial proton concentration (Fig. 8b). Consequently, proton concentration at the electrode/solution interface varies periodically due to the formation and subsequent escape of hydrogen bubbles as the deposit grows. According to the codeposition mechanism, the incorporation of phosphorus in the deposit depends on the $\mathrm{pH}$, i.e., proton concentration, of the solution regardless of direct or indirect codeposition mechanisms. ${ }^{1,13-17}$ Therefore, interfacial $\mathrm{pH}$ variations should cause the variation in the deposit phosphorus content as electroplating continues. For example, the lamellas observed on the deposit plated from the bath with the addition of $1 \mathrm{~g} \mathrm{dm}^{-3} \mathrm{H}_{3} \mathrm{PO}_{3}$ (Fig. 2b) are believed to be due to the slight variation in phosphorus content because the deposit still has a [100] texture, characteristic of the coarse columnar nickel grains. ${ }^{28}$ TEM also shows that the layer boundary seems to contain more phosphorus than the interior of each layer. Crousier et $a .^{29}$ have confirmed that the layered Ni-P electrodeposits consist alternately of layers with different phosphorus contents.

Other reactions causing changes of the $\mathrm{pH}$ at the interface potentially occur during electroplating. For example, reduction of $\mathrm{H}_{3} \mathrm{PO}_{3}$ to either phosphorus or phosphine consumes protons, while reduc- tion of phosphine in the presence of $\mathrm{Ni}^{2+}$ to phosphorus produces protons. ${ }^{1,13-17}$ Evolved gas bubbles also help to maintain the interfacial proton concentration to a value close to that of the solution. A lower current efficiency signifies that more hydrogen is discharged and a shorter time is required for the generated hydrogen bubbles to grow to their critical sizes for escaping from the cathode. This explains the observation that the thickness of the layer decreases with increasing bath $\mathrm{H}_{3} \mathrm{PO}_{3}$ concentration because the periodic alteration of the interfacial proton concentration is accelerated by adding $\mathrm{H}_{3} \mathrm{PO}_{3}$ to the bath. Finally, a homogeneous deposit (Fig. 2f) can be made with severe hydrogen evolutions, in agreement with the result that a homogeneous Ni-P electrodeposit is plated on a rotating disk electrode by means of increasing mass transport to the cathode. ${ }^{1}$

Internal stress of the deposit.-The flexible strip method used in this study measures the average stress ${ }^{21,32}$ of the deposit in which there could be highly localized stresses of both a tensile and compressive nature. However, the average stress of the deposit should reveal the most dominant mechanism for the evolvement of the local stress if an overall uniformity of the deposit through its thickness can be obtained. ${ }^{33}$ When electroplated in the nickel sulfamate bath with various amounts of $\mathrm{H}_{3} \mathrm{PO}_{3}$, all the Ni-P deposits studied exhibit a tensile stress that has a maximum at intermediate deposit phosphorus content. Furthermore, the internal stress exhibits a distinct change as the coating microstructure changes with the deposit phosphorus content. Therefore, the internal stress seems to be related to proton discharge and crystallite joining during electroplating.

A general review of the origins of stress in electrodeposits given by Weil summarizes five possible theories: crystallite joining, hydrogen, changes in foreign substances, excess energy, and lattice defects. ${ }^{32}$ Hydrogen incorporation can cause both tensile and compressive stresses. A compressive stress is induced when hydrogen either stays in the interstices of or forms gas pockets in the deposit, ${ }^{26,32}$ while a tensile stress is associated with the decrease in volume when the codeposited hydrogen leaves again. ${ }^{8,32,34}$ Because voids were hardly observed even in the deposit plated at $32 \%$ cathodic efficiency (Fig. 1 and 6), the gas pockets, if they exist in the deposit, are unlikely to play an important role in the internal stress of all the deposits investigated. Instead, tensile stresses can occur when the hydrogen, which is incorporated in the deposit as a result of proton discharge and hydrogen absorption, diffuses out of the deposit, because all of the deposits studied exhibit a tensile stress regardless of their phosphorus contents. Paseka ${ }^{7}$ studied evolution of hydrogen and its sorption in Ni-P electrodeposits and found that the amount of absorbed hydrogen depends on the deposit phosphorus content and has a maximum at intermediate deposit phosphorus content. Burchardt ${ }^{10}$ also noted a volcano-shaped curve for the dependence of the rate of the hydrogen evolution reaction (HER) on the deposit phosphorus content, signifying a maximum activity associated with the deposits with intermediate phosphorus content. Furthermore, the most active Ni-P electrodes absorb the largest amount of hydrogen. Because the internal stress vs. the deposit phosphorus content plot also shows a volcano-shaped curve (Fig. 7), the peak stress of the deposit is probably related to the escape of a maximum amount of absorbed hydrogen that is subsequently incorporated in the deposit with continued electroplating. Boric acid, which tends to stabilize the interfacial $\mathrm{pH}$ to a value close to the bulk nickel sulfamate solution, has been shown to effectively suppress hydrogen evolution during high-speed electroplating and thus produce the nickel films with low internal stresses. ${ }^{34}$

Another close-related phenomenon is the evolution of the grain structure and internal stress of the deposits with increasing deposit phosphorus content. The maximum tensile stress of the deposit occurs at critical deposit phosphorus content when the coating consists of fibrous grains that undergo the most serious lattice distortions among the deposits studied. Below this critical value the coating exhibits a columnar structure, while above that the coating displays an equiaxed grain structure. Consequently, the crystallite-joining theory might, to some extent, account for the internal stress of the deposit. For example, upon electrocrystallization, the crystallites, 
which form via three-dimensional nucleation, grow and touch each other. Subsequent coalescence causes a tensile stress because the different crystallites, when they touch each other, would be pulled together by a surface tension so as to reduce the total free surface energy. This pulling force depends on the grain shape, size, and preferred orientation of the deposit. For example, most deposits that exhibit relatively high internal stresses consist of columnar grains on which the pulling force developed upon merging the columnar grains together should be linear with the thickness of the deposit. ${ }^{32}$ Larger column grains could increase the internal stress because the boundary mismatch would be greater, but fewer unfilled gaps associated with larger grains would reduce the internal stress. The pure sulfamate nickel plated in this study has a relatively low stress because of its relatively coarse columnar grains with (200) texture. ${ }^{34}$ Phosphorus incorporation refines the grain structure and results in more randomized fibrous grains. The increase in mismatch between random fibrous grains and in unfilled gaps associated with the finer grains causes an increase in the internal stress. Meanwhile, the coalescence of these fibrous grains could result in serious lattice distortions induced by a larger pulling force. When phosphorus in the deposit exceeds a critical amount, the development of long fibrous grains is inhibited. Instead, equiaxed grains form (Fig. 4). As fibrous grains are replaced by equiaxed grains, one would expect a decreased tensile stress because smaller crystallites, as merging together, result in smaller pulling force. Smaller pulling forces induce fewer lattice defects in the deposit, as evident from the fact that fibrous grains contain more dislocations than equiaxed grains. However, as electroplating proceeds, nucleation, growth, and coalescence of the equiaxed grains on the existing coating layer might result in a complicated stress distribution through the thickness of the deposit. Finally, a slight decrease in the internal stress was observed as the deposit comprises amorphous matrix with dispersed nanocrystals. Apparently, near amorphous structure, lattice mismatch contributes less to the internal stress.

\section{Conclusions}

This study demonstrates that the hardness and internal stress of the Ni-P electrodeposit are well related to its microstructure, which changes with the phosphorus content in the deposit. Several key findings are summarized as the following.

1. More phosphorus is incorporated when more $\mathrm{H}_{3} \mathrm{PO}_{3}$ is added to the nickel sulfamate bath, while the current efficiency monotonously decreases with increasing bath $\mathrm{H}_{3} \mathrm{PO}_{3}$.

2. As the bath $\mathrm{H}_{3} \mathrm{PO}_{3}$ is increased, the hardness of the deposit increases abruptly, followed by a gradual increase, and finally a slight decrease as $40 \mathrm{~g} \mathrm{dm}^{-3} \mathrm{H}_{3} \mathrm{PO}_{3}$ is added. The tensile stress in the deposit also escalates with increasing bath $\mathrm{H}_{3} \mathrm{PO}_{3}$ and reaches a maximum value at $5 \mathrm{~g} \mathrm{dm}^{-3} \mathrm{H}_{3} \mathrm{PO}_{3}$. Further increase in bath $\mathrm{H}_{3} \mathrm{PO}_{3}$ reduces the tensile stress in the deposit.

3 . The overall structural evolution shown on chemically etched cross sections with increasing bath $\mathrm{H}_{3} \mathrm{PO}_{3}$ shows, in order, column, the coexistence of column and lamella, a characteristic layer, and finally a featureless structure.

4. Both columnar pure nickel and Ni-P electrodeposits exhibit a [100] texture, while layered Ni-P deposits generally display a random texture. The XRD pattern of the deposit that shows featureless after chemical etching contains broadened humps.

5 . When the nickel deposit is alloyed with phosphorus by adding $\mathrm{H}_{3} \mathrm{PO}_{3}$ in the nickel sulfamate bath, an initial incorporation of phosphorus refines the columnar grain structure and introduces more lattice defects. The development of columnar grains is inhibited and the equiaxed grains form as bath $\mathrm{H}_{3} \mathrm{PO}_{3}$ concentration exceeds a critical amount. Further increase in bath $\mathrm{H}_{3} \mathrm{PO}_{3}$ concentration results in the deposit composed of amorphous matrix dispersed with nanograins.

6. The layered structure associated with Ni-P deposits appears to be related to periodic variations in interfacial $\mathrm{pH}$, which changes with reduction of protons, $\mathrm{H}_{3} \mathrm{PO}_{3}$, and phosphine, as well as enhanced convection induced by evolved gas bubbles.

7. The fact that both the internal stress and amount of absorbed hydrogen have a maximum at intermediate phosphorus contents suggests that hydrogen incorporation in and subsequent escape from the deposit plays an important role in the internal stress of Ni-P electrodeposits.

\section{Acknowledgments}

This research was supported by the National Science Council, Republic of China, under grant no. 91-2216-E-002-040. L. C. Wang, National Sun Yat-sen University, is recognized for her assistance with the TEM work. This study made use of the electron probe microanalyzer and electron microscopes of National Taiwan University and electron microscopes of National Sun Yat-sen University, supported by the National Science Council, Republic of China.

National Taiwan University assisted in meeting the publication costs of this article.

\section{References}

1. M. Ratzker, D. S. Lashmore, and K. W. Pratt, Plat. Surf. Finish., 73(9), 74 (1986)

2. R. Weil, J. H. Lee, and K. Parker, Plat. Surf. Finish., 137(2), 76 (1989).

3. C. J. Chen and K. L. Lin, Thin Solid Films, 370, 106 (2000).

4. B. P. Daly and F. J. Barry, Int. Mater. Rev., 48, 326 (2003).

5. C. C. Hu and A. Bai, J. Appl. Electrochem., 31, 565 (2001).

6. C. C. Hu and A. Bai, Mater. Chem. Phys., 77, 215 (2003).

7. I. Paseka, Electrochim. Acta, 40, 1633 (1995).

8. I. Paseka, Electrochim. Acta, 47, 921 (2001).

9. T. Burchardt, Int. J. Hydrogen Energy, 25, 627 (2000)

10. T. Burchardt, V. Hansen, and T. Valand, Electrochim. Acta, 46, 2761 (2001).

11. R. K. Shervedani and A. Lasia, J. Electrochem. Soc., 144, 511 (1997).

12. A. Brenner, Electrodeposition of Alloys, Vol. II, Academic Press, New York (1963).

13. T. Morikawa, T. Nakade, M. Yokoi, Y. Fukumoto, and C. Iwakura, Electrochim. Acta, 42, 115 (1997).

14. R. L. Zeller III and U. Landau, J. Electrochem. Soc., 139, 3464 (1992)

15. T. M. Harris and Q. D. Dang, J. Electrochem. Soc., 140, 81 (1993).

16. Y. Zeng and S. Zhou, J. Electroanal. Chem., 469, 79 (1999).

17. M. Saitou, Y. Okudaira, and W. Oshikawa, J. Electrochem. Soc., 150, C140 (2003).

18. E. Bredael, B. Blanpain, J. P. Celis, and J. R. Roos, J. Electrochem. Soc., 141, 294 (1994).

19. E. Vafaei-Makhsoos, E. L. Thomas, and L. E. Toth, Metall. Trans. A, 9, 1449 (1978)

20. K. Shimizu, G. E. Thompson, G. C. Wood, and K. Kobayashi, Philos. Mag. Lett., 61, 43 (1990)

21. R. D. Fisher, J. Electrochem. Soc., 109, 479 (1962)

22. D. Baudrand, Met. Finish., 94(7), 15 (1996).

23. M. H. Seo, J. S. Kim, W. S. Hwang, D. J. Kim, S. S. Hwang, and B. S. Chun, Surf. Coat. Technol., 176, 135 (2004).

24. G. McMahon and U. Erb, J. Mater. Sci. Lett., 8, 865 (1989).

25. R. Narayan and M. N. Mungole, Surf. Technol., 24, 233 (1985).

26. H. D. Park, D. Chang, K. H. Lee, and S. G. Kang, Plat. Surf. Finish., 88(12), 64 (2001).

27. J. W. Dini, Electrodeposition, 1st ed., p. 141, Noyes Publications, Park Ridge, NJ (1993).

28. C. S. Lin, K. C. Peng, P. C. Hsu, L. Chang, and C. H. Chen, Mater. Trans., JIM, 41, 777 (2000)

29. J. Crousier, Z. Hanane, and J.-P. Crousier, Thin Solid Films, 248, 51 (1994).

30. R. L. Zeller III and U. Landau, J. Electrochem. Soc., 137, 1107 (1990).

31. J. Amblard, I. Epelboin, M. Froment, and G. Maurin, J. Appl. Electrochem., 9, 233 (1979).

32. R. Weil, Plating, 58(2), 137 (1971)

33. G. S. Sotirova-Chakarova and S. A. Armyanov, J. Electrochem. Soc., 137, 3551 (1990).

34. Y. Tsuru, M. Nomura, and F. R. Foulkes, J. Appl. Electrochem., 32, 629 (2002). 